\title{
Produção e composição química do leite de vacas em lactação mantidas a pasto submetidas à diferentes sistemas alimentares
}

\author{
Production and chemical composition of lactating dairy cows on pasture submitted to \\ different feeding systems
}

\author{
CARDOSO, Rogério Bernardo ${ }^{1 *}$; PEDREIRA, Márcio dos Santos ${ }^{2}$; RECH, Carmen \\ Lucia de Souza ${ }^{3}$; SILVA, Herymá Giovane de Oliveira ${ }^{3}$; RECH, José Luiz ${ }^{3}$; SCHIO, \\ Alex Resende ${ }^{4}$; AGUIAR, Luzyanne Varjão ${ }^{4}$; SILVA, Abias Santos ${ }^{4}$; SILVA, Henrique \\ Almeida da ${ }^{4}$
}

\footnotetext{
${ }^{1}$ Universidade Estadual do Sudoeste da Bahia, Programa de Pós-Graduação em Zootecnia Itapetinga, Bahia, Brasil.

${ }^{2}$ Universidade Estadual do Sudoeste da Bahia, Departamento de Tecnologia Rural Itapetinga, Bahia, Brasil.

${ }^{3}$ Universidade Estadual do Sudoeste da Bahia, Departamento de Zootecnia, Itapetinga, Bahia, Brasil.

${ }^{4}$ Universidade Estadual do Sudoeste da Bahia, Itapetinga, Bahia, Brasil.

*Endereço para correspondência: rogeriobernardors@hotmail.com
}

\section{RESUMO}

Objetivou-se avaliar o consumo, coeficiente de digestibilidade dos nutrientes, produção e composição química do leite de vacas em lactação mantidas a pasto submetidas à diferentes sistemas alimentares: pasto exclusivo $(\mathrm{PE})$; pasto associado à cana-de-açúcar e ureia a $1 \%$ da matéria natural total (PCU); pasto associado a $4 \quad \mathrm{~kg}^{-1} \mathrm{dia}^{-1}$ de suplemento concentrado (PSC); pasto associado à silagem de sorgo e $2 \mathrm{~kg} \mathrm{dia}^{-1}$ de suplemento concentrado (PSC), e pasto associado à silagem de sorgo (PSS). O delineamento experimental foi quadrado latino $5 \times 5$, constituído de cinco períodos experimentais, com quatorze dias de adaptação e cinco dias de coleta. O consumo matéria seca do pasto, matéria seca total, matéria seca em relação ao peso corporal, fibra em detergente neutro e nutrientes digestiveis totais, não apresentaram efeito $(\mathrm{P}>0,10) \mathrm{em}$ função dos sistemas alimentares.Constatou-se efeito $(\mathrm{P}<0,10)$ sobre o consumo de proteína bruta. No que se refere ao pasto associado ao suplemento concentrado, observou-se o maior consumo $1,50 \mathrm{~kg} \mathrm{dia}{ }^{-1}$, todavia, para extrato etéreo o pasto associado à silagem de sorgo e suplemento concentrado $0,19 \mathrm{~kg} \mathrm{dia}^{-1}$, carboidrato não fibroso para pasto associado ao suplemento concentrado $2,18 \mathrm{~kg} \mathrm{dia}^{-1}$, digestibilidade do extrato etéreo para pasto associado ao suplemento concentrado $77,79 \mathrm{~kg}$ $\mathrm{dia}^{-1}$, possivelmente pelas variações nutricionais dos suplementos. Portanto nas condições desta pesquisa no tocante ao período primavera-verão, recomenda-se para vacas mestiças holandês $\mathrm{x}$ zebu com produção média de $15 \mathrm{~kg}$ leite $\operatorname{dia}^{-1} \mathrm{o}$ sistema alimentar pasto exclusivo de Urocloa decumbens, pois para a produção e composição química do leite é eventualmente mais viável.

Palavras-chave: associado, consumo, suplemento

\section{SUMMARY}

This study aimed to evaluate the intake, digestibility coefficient of nutrients, production and chemical composition of lactating dairy cows on pasture submitted to different feeding systems: exclusive pasture (PE); pasture associated with sugarcane and urea $1 \%$ of the total natural matter (PCU); pasture associated with $4 \mathrm{~kg} \mathrm{day}^{-1}$ concentrate supplement (PSC); pasture associated with sorghum silage and $2 \mathrm{~kg}$ day ${ }^{-1}$ concentrate supplement (PSC), and pasture associated with sorghum silage (PSS). The experimental design was a Latin square $5 \mathrm{x}$ 5 , consisting of five experimental periods, with fourteen days of adaptation and five days of collection. Consuming dry matter pasture, total dry matter, dry matter in relation to body 
weight, neutral detergent fiber and totals digestible nutrients, showed no effect $(\mathrm{P}>0.10)$ depending on the feeding systems. It was observed effect systems $(\mathrm{P}<0.10)$ on the consumption of crude protein pasture associated with for the concentrated supplement was observed higher consumption $1.50 \mathrm{~kg}$ day $^{-1}$, still, extract ethereal or associated to silage sorghum grass and concentrated supplement $0.19 \mathrm{~kg} \mathrm{day}^{-1}$, non-fibrous carbohydrate for pasture associated with the concentrated supplement $2.18 \mathrm{~kg} \mathrm{dia}{ }^{-1}$, digestibility of ethereal extract for pasture associated with the concentrate supplement77.79 kg day ${ }^{-1}$, possibly due to nutritional variations of supplements. Therefore under the conditions of this research regarding the spring-summer period, it is recommended for Dutch-zebu crossbred cows with an average production of $15 \mathrm{~kg}$ milk day ${ }^{-1}$, the exclusive pasture system of Urocloa decumbens, since for the production and chemical composition of the milk Is more feasible.

Keywords: associate, consumption, supplement

\section{INTRODUÇÃO}

As características climáticas afetam diretamente a potencialidade pecuária, nesse sentido, na época seca ocorre queda na disponibilidade e qualidade da forragem, devido à escassez e irregularidade de chuvas, associadas à altas temperaturas, o que diminui a lucratividade do setor, seja por menor produção de leite, seja no aumento do fornecimento de alimento concentrado para atendimento das exigências animais (WANDERLEY et al., 2012).

Visando estabecer o potencial produtivo de gramíneas para a produção leiteira Benedetti et al. (2012) avaliaram a composição bromatológica e a produção de leite de vacas mestiças pastejando em piquetes de capim Napier (Pennisetum purpureum) (NAP), Brachiaria decumbens (BRA) e Colonião (Panicum maximum) (COL) verificaram os seguintes valores para
NAP, BRA e COL: matéria orgânica 91,9; 92,8; 93,7; PB 15,05; 11,9; 14,1; energia bruta $4.33 ; 4.500 ; 4.500 ;$ FDN 76,$9 ; 76,9 ; 78,8$; FDA 56,$2 ; 54,1 ; 55,8$; celulose 47,$3 ; 46,3 ; 46,5$; hemicelulose 20,$7 ; 22,6 ; 27$ e lignina 7,$6 ; 6,0 ; 7,9$; produção de leite $\mathrm{kg} \mathrm{dia}^{-1} 15,46 ; 14,31$; 16,07; gordura (\%) 4,0; 4,18; 3,90; proteína $(\%) 2,44 ; 2,49 ; 2,44$, extrato seco total 12,$45 ; 12,49 ; 12,33$. Além Disso, verificaram que entre as forragens pastejadas, a Brachiaria apresentou o menor teor de proteína bruta e o Napier o menor teor de energia bruta, sendo esse fato, provavelmente, consequência do maior teor de minerais presentes nessa forragem. Para produção de leite o capim NAP e COL foram superiores, contudo verificaram que as espécies forrageiras não influíram na composição do leite das vacas. Deste modo concluiram que os capins NAP, BRACH e COL apresentam-se como boas alternativas para a produção de leite a pasto.

Devido a sazonalidade anual, verifica-se redução na oferta de forragem e isso ocasiona um déficit alimentar. Assim, o sucesso na produção de leite é baseado no uso de pastagens de excelente valor nutritivo e que sejam manejadas com o objetivo de possibilitar elevada ingestão de nutrientes (Ribeiro Filho et al., 2009). Diante do exposto, os sistemas alimentares são alternativas que podem ser utilizadas para auxiliar na alimentação do rebanho durante o período de escassez de alimentos; desta forma contribuem para suprir as exigências nutricionais de vacas lactantes. Nessa perspectiva, objetivouse avaliar o consumo, o coeficiente de digestibilidade dos nutrientes bem como a produção e composição química do leite de vacas em lactação mantidas a pasto submetidas a diferentes sistemas alimentares. 


\section{MATERIAL E MÉTODOS}

O experimento foi conduzido na Universidade Estadual do Sudoeste da Bahia, no setor de bovinocultura leiteira, localizada no município de Itapetinga-BA, que apresenta as seguintes coordenadas geográficas: o paralelo $15^{\circ} 14$ de latitude sul e o meridiano de $40^{\circ} 13^{\prime}$ de longitude oeste e altitude média de $269 \mathrm{~m}$. Este foi realizado entre os dias 19 de novembro de 2013 a 25 de fevereiro de 2014. Foram registrados durante os períodos experimentais índices pluviométricos de $318,97 \mathrm{~mm}$. Entre os meses de novembro e dezembro, registrou-se $231,97 \mathrm{~mm}$ época correspondente ao final da primavera, de um total de $537 \mathrm{~mm}$ no ano de 2013. Entretanto, no verão, de janeiro a fevereiro constatouse índice pluviométrico de $86,6 \mathrm{~mm}$, no total de 391,6 mm em 2014.

Foram utilizadas 5 vacas mestiças Holandesas x Zebu, com peso médio de $599 \pm 12,66 \mathrm{~kg}$, sendo que das cinco, três vacas encontravam-se na fase de pico de lactação e duas no terço médio desse mesmo estágio, distribuídas no delineamento experimental quadrado latino $5 \times 5$, constituído por cinco tratamentos e cinco períodos experimentais de dezenove dias; sendo quatorze dias de adaptação e cinco dias de coleta perfazendo noventa e cinco dias de duração. As vacas foram ordenhadas diariamente às $06 \mathrm{~h} 30$, posteriormente foram mantidos em baias individuais com cocho $\mathrm{e}$ bebedouro de tamanho $5 \times 1,80 \mathrm{~m}^{2}$ por $01 \mathrm{~h} 00$, com alimentações fornecidas às 07h00. Além disso, eram submetidas a seus respectivos tratamentos: pasto exclusivo (PE) de capim Urochloa decumbens; pasto associado à cana-deaçúcar e ureia a $1 \%$ da matéria natural total (PCU); pasto associado a $4 \mathrm{~kg} \mathrm{dia}^{-1}$ de suplemento concentrado (PSC); pasto associado à silagem de sorgo e 2 $\mathrm{kg}$ dia $^{-1}$ de suplemento concentrado (PSSC), e pasto associado à silagem de sorgo (PSS). Desta forma, foram ofertados com base na matéria seca, as seguintes quantidades: para o sistema alimentar PCU $20 \mathrm{~kg}$ de cana-de-açucar corrigida com ureia a $1 \%$ da matéria natural. Todavia, ofertou-se $10 \mathrm{~kg}$ de silagem de sorgo para os seguintes tratamentos PSSC; PSS respectivamente. A quantidade dos suplementos ofertados foi reajustada, conforme o consumo do dia anterior, permitindo disponibilidade entre 5 e $10 \%$ de sobras como margem de segurança.

Após a saída das vacas das baias às 08h00, foram colhidas amostras das sobras dos suplementos fornecidos, por conseguinte, foram colhidas amostras de pasto por meio do pastejo simulado. Após o término do período de alimentação, as vacas foram direcionadas ao piquete com tamanho médio de área de $7,500 \mathrm{~m}^{2}$, onde permaneceram por um período de aproximadamente $24 \mathrm{~h} 00$, perfazendo um sistema de pastejo rotacionado entre 16 piquetes. Para tanto, foi respeitado o controle de entrada dos animais nos piquetes de acordo com a altura do pasto, considerando-se $30 \mathrm{~cm}$ para a entrada e $15 \mathrm{~cm}$ para a saída. A relação volumoso: concentrado utilizada para compor os sistemas alimentares foram 60:40. A suplementação concentrada foi definida pelo balanceamento das dietas para conter nutrientes suficientes para mantença e produção de $15 \mathrm{~kg}$ de leite dia $^{-1}$, de acordo com o Nacional Research Council (NRC, 2001). Os ingredientes utilizados para formulação do concentrado, para suprir as exigências nutricionais das vacas lactantes por cinco períodos experimentais, estão descritos na Tabela 1. 
Tabela 1. Proporções dos ingredientes com base na matéria seca, que constituíram o suplemento concentrado para vacas em lactação

\begin{tabular}{lc}
\hline Ingredientes & Nível de inclusão em (kg) \\
\hline Milho grão moído & 68 \\
Farelo de Trigo & 25 \\
Ureia & 0,4 \\
Mineral & 0,3 \\
\hline${ }^{1}$ Composição: Cálcio 200 g; Cobalto $80 \mathrm{mg} ;$ \\
Cobre 1.350 mg; Enxofre 18g; Ferro $1.450 \mathrm{mg} ;$ \\
Flúor (max) 850 mg; Fósforo 85 g; Iodo $90 \mathrm{mg} ;$ \\
Magnésio 15 g; Manganês $1.170 \mathrm{mg}$; Selênio \\
22 mg; Sódio 90,00 g; Zinco 5.800 mg.
\end{tabular}

A composição bromatológica dos sistemas alimentares fornecidos às vacas lactantes estão descritas na Tabela 2 .

A composição química do solo equivalente à área de implantação da cultura do capim Urocloa decumbens. está descrita na Tabela 3.

A área experimental possui solo classificado como podozólico vermelho amarelo. Conquanto, a composição física do solo na área experimental está exposta na Tabela. 4.

Tabela 2. Composição bromatológica dos sistemas alimentares

\begin{tabular}{lccccc}
\hline \multirow{2}{*}{ Componentes } & \multicolumn{5}{c}{ Sistemas alimentares } \\
\cline { 2 - 5 } & PE & PCU & PSC & PSSC & PSS \\
\hline MS & 25,22 & 26,54 & 87,98 & 31,97 & 21,98 \\
MO & 92,91 & 97,86 & 95,57 & 93,52 & 91,03 \\
PB & 9,6 & 13,11 & 19,91 & 15,19 & 8,37 \\
EE & 1,39 & 0,87 & 2,17 & 2,87 & 1,29 \\
MM & 7,09 & 2,12 & 4,01 & 6,56 & 8,95 \\
LIG & 4,03 & 4,35 & 1,25 & 3,97 & 5,21 \\
FDN & 69,3 & 64,66 & 24,32 & 50,03 & 63,48 \\
FDA & 33,69 & 29,17 & 5,84 & 23,33 & 38,07 \\
CNF & 11,92 & 19,42 & 51,44 & 49,54 & 18,49 \\
\hline MS mate
\end{tabular}

$\mathrm{MS}=$ matéria seca; $\mathrm{MO}=$ matéria orgânica; $\mathrm{PB}=$ proteína bruta, $\mathrm{EE}=$ extrato etéreo, $\mathrm{MM}=$ matéria mineral; $\mathrm{LIG}=$ lignina; FDN = fibra em detergente neutro; FDA = fibra em detergente ácido; $\mathrm{CNF}=$ carboidrato não fibroso; $\mathrm{PE}$, = pasto exclusivo; $\mathrm{PCU}=$ pasto associado á cana-de-açucar e ureia; $\mathrm{PSC}=$ pasto associado ao suplemento concentrado; PSSC = pasto associado á silagem de sorgo e suplemento concentrado; PSS = pasto com silagem de sorgo.

Tabela 3. Composição química do solo

\begin{tabular}{cccccccccccc}
\hline $\mathrm{pH}$ & $* \mathrm{mg} / \mathrm{dm}^{3}$ & \multicolumn{1}{c}{${ }^{*} \mathrm{cmol}_{\mathrm{c}} / \mathrm{dm}^{3}$ de solo } & & $\%$ \\
\hline$\left(\mathrm{H}^{2} \mathrm{O}\right)$ & $\mathrm{P}$ & $\mathrm{K}^{+}$ & $\mathrm{Ca}^{2+}$ & $\mathrm{Mg}^{2+}$ & $\mathrm{Al}^{3+}$ & $\mathrm{H}^{+}$ & $\mathrm{Na}^{+}$ & $\mathrm{S} . \mathrm{B}$. & $\mathrm{T}$ & $\mathrm{T}$ & $\mathrm{V}$ \\
\hline 6 & 4 & 0,26 & 2,0 & 1,1 & 0,1 & 2,4 & 0,11 & 3,5 & 3,6 & 6 & 58 \\
\hline
\end{tabular}

$\mathrm{S} . \mathrm{B}=$ Soma de Bases Trocaveis; $\mathrm{t}=\mathrm{CTC}$ efetiva; $\mathrm{T}=\mathrm{CTC} ; \mathrm{V}=$ Saturação de Bases.

Tabela 4. Composição física do solo

\begin{tabular}{ccccccc}
\hline \multicolumn{3}{c}{ Frações da amostra total \% } & \multicolumn{5}{c}{ Comp. Granulométrica (tfsa g/kg) } \\
\hline Calh. & Casc. & Terra fina & Areia grossa & Areia fina & Silte & Argila \\
$200-20$ & $20-2$ & $<2$ & $2-0,20$ & $0,20-0,05$ & $0,05-0,002$ & $<0,002$ \\
Mm & $\mathrm{Mm}$ & $\mathrm{Mm}$ & $\mathrm{Mm}$ & $\mathrm{Mm}$ & $\mathrm{Mm}$ & $\mathrm{Mm}$ \\
0 & 0 & 100 & 500 & 370 & 30 & 100 \\
\hline
\end{tabular}


As vacas foram pesadas no início e no final de cada período para determinar a variação de peso corporal. As fezes foram coletadas diretamente da ampola retal, em horários alternados - às $08 \mathrm{~h} 00$, 10h00, 12h00, $14 \mathrm{~h} 00$ e 16h:00 posteriormente acondicionadas em sacos plásticos e armazenadas em freezer a $-10^{\circ} \mathrm{C}$ para posteriores análises. No laboratório de Nutrição Animal da Universidade Estadual do Sudoeste da Bahia - Campus de Itapetinga, foram determinadas as análises bromatológicas dos sistemas alimentares para determinação dos teores de matéria seca, extrato etéreo, matéria mineral, fibra em detergente neutro, fibra em detergente ácido $\mathrm{e}$ proteína bruta segundo (RECH et al., 2010).

As amostras de leite foram colhidas às 06h30 e o método utilizado foi a ordenha mecânica, posteriomente a produção foi registrada mediante pesagem diária em balança analógica com capacidade para $30 \mathrm{~kg}$. Após a pesagem, retirou-se alíquotas de 500 $\mathrm{mL}$, que foram armazenadas em potes plásticos e acondicionadas em freeser a $3^{\circ} \mathrm{C}$ sendo posteriormente analisadas. Nessa análise, foram determinados os teores de gordura por meio do método butirométrico, sendo feita a leitura na escala do butirômetro de Teicher; no entanto proteína foi analisada pelo método Kjedahl, utilizando-se o fator de conversão de 6,38 para o cálculo da proteína total; (BRASIL, 2009). As concentrações de NUL foram estimadas utilizando-se o equipamento ChemSpeck $150 \AA$, por meio do método enzimático e espectrofotométrico de trans-reflectância.

O Consumo de volumoso foi calculado da seguinte forma:

$$
\operatorname{CMSF}(\mathrm{kg} / \mathrm{dia})=\frac{(\mathrm{CMNF}(\mathrm{kg} / \mathrm{dia}) \times \% \mathrm{MSF})}{100} \frac{\mathrm{SF}(\mathrm{Kg} / \mathrm{dia}) \times \% \mathrm{MSS}}{100}
$$

Em que: $\mathrm{CMSF}=$ consumo de MS do fornecido; $\mathrm{CMNF}=$ consumo $\mathrm{de}$ matéria natural do fornecido, $\mathrm{SF}=$ Sobras do fornecido, $\% \mathrm{MSS}=\%$ de MS das sobras, segundo Detmann et al. (2012).

Diariamente, foi registrada a quantidade de ração oferecida e as sobras foram retiradas e pesadas, objetivando avaliar o consumo médio diário.

O consumo de nutrientes foi calculado por meio da fórmula:

$\mathrm{CN}=\left[\begin{array}{lll}\text { MSo } & \mathrm{x} & \mathrm{NMSo}\end{array}\right)(\mathrm{MSs} \quad \mathrm{x}$ NMSs)]/100

Em que: $\mathrm{CN}=$ consumo de nutrientes (g); MSo = matéria seca oferecida (g); MSS = matéria seca das sobras (g); NMSo $=$ nutriente na matéria seca oferecida (\%); NMSs $=$ nutriente na matéria seca das sobras (\%).

Para identificação da produção fecal foi utilizado o indicador externo dióxido de titânio $\left(\mathrm{TIO}_{2}\right)$. A excreção fecal foi calculada com a seguinte fórmula:

$\mathrm{EF}(\mathrm{kg} / \mathrm{dia})=\left(\mathrm{PTIO}_{2} \mathrm{OFg} / \mathrm{TIO}_{2} \mathrm{ASE} \%\right)$ $\mathrm{x} 100$

Em que: $\mathrm{EF}=$ excreção fecal $(\mathrm{kg} / \mathrm{dia})$, $\mathrm{PTIO}_{2} \mathrm{Og} / \mathrm{TIO}_{2}=$ pureza do dióxido de titânio oferecido em gramas, $\mathrm{TIO}_{2} \mathrm{ASE}$ $\%=$ Dióxido de titânio presente na \% de MS.

Os carboidratos não fibrosos (CNF) das amostras, que não continham ureia, foram calculados pela equação proposta:

$\mathrm{CNF}=100-(\% \mathrm{~PB}+\% \mathrm{EE}+\%$ Cinzas + $\% \mathrm{FDN}$ ) 
Os cálculos referentes ao consumo, excreção fecal e carboidrato não fibroso foram efetuados segundo as equações propostas por (DETMANN et al., 2012).

Para determinação dos coeficientes de digestibilidade aparente total, foi utilizada a fibra em detergente neutro indigestível (FDNi) como indicador interno, as amostras dos alimentos, sobras e das fezes, obtida após a incubação no rúmen de dois animais fistulados por 288 horas, tendo o resíduo classificado como indigestível (DETMANN et al., 2012). Foram pesadas e registradas, diariamente, as quantidades de leite ordenhadas de cada animal. A produção do leite para $4 \%$ de gordura (PLCG 4\%) foi realizada segundo o NRC (2001), empregando-se a equação: $\mathrm{LCG} 4 \%=(0,4 \times \mathrm{kg}$ leite $)+$ (15 x kg de gordura do leite).

Os resultados de consumo, digestibilidade, desempenho e composição química do leite foram analisados estatisticamente por meio de Análises de Variância (ANOVA) e as médias comparadas pelo teste de Tukey adotando-se o nível de significância de
0,10 de probabilidade de erro, para analisar o efeito dos sistemas alimentares sobre os parâmetros mencionados. Deste modo, o teste de Tukey foi escolhido por ser um dos testes de comparação de média mais utilizados, sendo bastante rigoroso e de fácil aplicação, no qual não permite comparar grupos de tratamentos entre si. Ademais, foi utilizado também para testar toda e qualquer diferença entre duas médias de tratamento. Contudo, o delineamento experimental utilizado foi o quadrado latino, além de ter utilizado o procedimento do Sistema de Análises Estatísticas e Genéticas SAEG (UFV, 2007).

\section{RESULTADOS E DISCUSSÃO}

Não houve efeito $(\mathrm{P}>0,10)$ para $\mathrm{o}$ consumo de matéria seca do pasto (CMSP), matéria seca total (CMST) e matéria seca em percentual do peso corporal (MS\%PC), fibra em detergente neutro (FDN) e nutrientes digestíveis totais (NDT) em função dos sistemas alimentares (Tabela 5).

Tabela 5. Consumo de nutrientes dos sistemas alimentares

\begin{tabular}{lcccccccc}
\hline \multirow{2}{*}{ Variável } & \multicolumn{9}{c}{ Sistemas alimentares } & \multirow{2}{*}{ EPM } & \multirow{2}{*}{ P } \\
\cline { 2 - 6 } & PE & PCU & PSC & PSSC & PSS & & \\
\hline MSP & 12,76 & 11,94 & 11,56 & 11,05 & 11,39 & 1,46 & 0,51 \\
MST & 12,76 & 12,34 & 13,25 & 13,32 & 11,73 & 1,45 & 0,45 \\
MS\%PC & 2,25 & 2,16 & 2,38 & 2,35 & 2,08 & 0,26 & 0,34 \\
PB & $1,26^{\text {abc }}$ & $1,23^{\mathrm{bc}}$ & $1,50^{\mathrm{a}}$ & $1,43^{\mathrm{ab}}$ & $1,16^{\mathrm{c}}$ & 0,20 & 0,019 \\
FDN & 8,84 & 8,51 & 8,44 & 8,65 & 8,09 & 0,96 & 0,82 \\
EE & $0,16^{\mathrm{b}}$ & $0,15^{\mathrm{b}}$ & $0,18^{\mathrm{ab}}$ & $0,19^{\mathrm{a}}$ & $0,15^{\mathrm{b}}$ & 0,54 & 0,015 \\
CNF & $1,54^{\mathrm{b}}$ & $1,53^{\mathrm{b}}$ & $2,18^{\mathrm{a}}$ & $2,08^{\mathrm{a}}$ & $1,43^{\mathrm{b}}$ & 3,56 & 0,003 \\
NDT & 6,32 & 6,08 & 6,84 & 6,66 & 5,74 & 0,84 & 0,21 \\
\hline
\end{tabular}

Médias seguidas de mesma letra na linha não diferem entre si pelo teste Tukey ao nível de (10\%) de probabilidade. $\mathrm{EPM}=$ Erro padrão da média; $\mathrm{P}=$ Probabilidade de erro. $\mathrm{MSP}=$ matéria seca do pasto; $\mathrm{MST}=$ matéria seca total; $\mathrm{MS} \% \mathrm{PC}=$ matéria seca em percentagem do peso corporal; $\mathrm{PB}=$ proteína bruta; FDN = fibra em detergente neutro; $\mathrm{EE}=$ extrato etéreo; $\mathrm{CNF}=$ carboidrato não fibroso; $\mathrm{NDT}=$ nutrientes digestíveis totais; $\mathrm{PE}=$ pasto exclusivo; $\mathrm{PCU}=$ pasto associado à cana-de-açúcar e ureia; PSC $=$ pasto associado ao suplemento concentrado; PSSC $=$ pasto associado à silagem de sorgo e suplemento concentrado ; PSS = pasto associado à silagem de sorgo. 
Os sistemas alimentares apresentaram reduzido acréscimo sobre o consumo matéria de matéria seca total (CMST) 12,76; 12,34; 13,25; 13,52; $11,73 \mathrm{Kg} \mathrm{dia}^{-1}$. Assim, foi maximizado pela ingestão de pasto 12,$76 ; 11,94$; 11,$56 ; 11,05 ; 11,39 \mathrm{Kg} \mathrm{dia}^{-1}$, para PE; PCU; PSC; PSSC, PSS, respectivamente. Provavelmente, devido às influências climáticas promovidas pelo período secaáguas, constatou-se mudanças no hábito alimentar dos animais. Segundo Berchielli et al. (2011), o consumo é influenciado pelas características do alimento, do animal e do ambiente.

Durante o período seco, com a maturidade fisiológica da forrageira, elevou-se o percentual de FDN (Tabela 2), ocorreu o espeçamento da parede celular potencializou o complexo fenólico carboidrato, prejudicando a IMS dos sistemas alimentares. A lignocelulose limita ação dos microrganismos no rúmen, prejudica a disgetão dos carboidratos, reduz o suprimento energético do animal. A IMS de vacas leiteiras é regulada por distenção no RR depende da exigência de energia do animal e do efeito de enchimento da dieta oferida (BERCHIELLI et al., 2011).

Porém, no decorrer do periodo das águas, verificou-se excesso de umidade da pastagem considerando o período de rebrota. Deste modo, os perfilhos jovens do pasto justifica-se o reduzido teor de matéria seca (Tabela 2). Nesse estágio, a pastagem de Urocloa decunbens apresentou-se baixo teor de fibra e uma elevada densidade energética, que proporcionou uma indução da saciedade dos animais. Sendo assim, a preferência pelo broto inibiu a ingestão dos sistemas alimentares.

Conquanto o teor de MS ideal para vacas em lactação está entre 50 a $75 \%$. Em pastejo de Urocloa decumbens, os bovinos consomem $90 \%$ de forragem verde com grande participação da fração laminar foliar da pastagem, os valores observados em percentual do peso corporal estão bem próximos àqueles preconizados para vacas de leite consumindo capim Urocloa decumbens, independente da oferta de forragem (Tabela 5).

Os sistemas alimentares PSSC e o PSC obteve o maior consumo de MST 13,$32 ; 13,25 \mathrm{~kg}$ dia $^{-1}$ respectivamente. Possivelmente pois a suplementação auxíliou a corrigir o deficit nutricional da forrageira, suprindo PB; NDT e minerais proporcinando assim, incremento na IMS e na performance animal sob pastejo. Segundo Reis et al. (2009), mesmo havendo disponibilidade de fibra potencialmente digestível nos pastos, no período seco a proteína é o nutriente que mais limita o desempenho animal. Dessa forma, o propósito de suplementação nesta fase é adequar os níveis de nitrogênio deficientes nas dietas dos animais, de tal forma a aumentar a eficiência de degradação da fração fibrosa e, consequentemente, a taxa de passagem e o consumo de matéria seca da forragem. O sistema alimentar que verificou-se o menor consumo de MS foi o PSS $11,73 \mathrm{~kg}$ $\mathrm{dia}^{-1}$, provavelmente em decorrência da composição química, e do processo fermentativo da silagem pois o pasto obteve percentuais elevados de carboidratos fibrosos para FDN 69,3\%; FDA $33,69 \%$, bem como para silagem FDN $63,48 \%$; FDA $38,07 \%$ deste modo afetou-se a IMS por impedimento fisico do consumo (Tabela 2). No entanto, o processo fermentativo da silagem promove redução nos teores de carboidratos solúveis e de proteína verdadeira, ocorrendo elevação na concentração de ácidos orgânicos e $\mathrm{N}$ não protéico, com consequente redução do valor nutritivo, decréscimo no consumo e na utilização dos nutrientes provenientes das silagens. (REIS et al., 2006). 
O consumo de proteína bruta (PB), extrato etéreo (EE), e carboidratos não fibrosos (CNF) apresentaram efeito $(\mathrm{P}<0,10)$ em função dos sistemas alimentares (Tabela 5). Provavelmente isso ocorre devido às variações dos nutrientes verificadas com base na MS dos tratamentos (Tabela 2). O sistema alimentar PSC apresentou o maior consumo de PB 1,50 $\mathrm{kg} \mathrm{dia}^{-1}$ (Tabela 5), provavelmente pelo maior percentual de proteína proporcionado pelo suplemento concentrado (Tabela 2). O teor de proteína na dieta tem correlação positiva com o consumo, sendo este efeito proveniente parcialmente do aumento da proteína degradável no rúmen e melhoria na digestibilidade dos alimentos.

Os sistemas alimentares apresentaram efeito sobre o consumo de extrato etéreo $(\mathrm{P}<0,10)$ possivelmente, devido a variação do teor do nutriente nos sistemas alimentares testados (Tabela 2) o sistema alimentar PSSC apresentou o maior consumo $0,19 \quad \mathrm{~kg} \quad \mathrm{dia}^{-1}$ possivelmente devido a maior IMS (Tabela 5).

Observou-se efeito $(\mathrm{P}<0,10)$ para o consumo de carboidratos não fibrosos em função dos sistemas alimentares, a máxima ingestão do nutriente foi observada para o sistema alimentar PSC $\mathrm{kg} \mathrm{dia}^{-1}$, que proporcionou uma variação no consumo de $52,45 \%$ em relação ao PSS 2,18 e $1,43 \mathrm{~kg}$ dia $^{-1}$ respectivamente. Possivelmente, o consumo foi maximizado pelo suplemento concentrado, que obteve maior percentual de carboidratos não fibrosos com base na MS (Tabela 2). Silva et al. (2009) e Martins et al. (2011) encontraram valores superiores de CNF 2,$20 ; 1,83 \mathrm{~kg} \mathrm{dia}^{-1}$, respectivamente, o que provavelmente esteja associado a uma maior ingestão de matéria seca. $\mathrm{O}$ consumo de NDT não apresentou efeito $(\mathrm{P}>0,10)$, foi observado a maior ingestão do nutriente para o sistema alimentar PSC. Segundo o NRC (2001), para vacas leiteiras de produção média de $15 \mathrm{~kg} \mathrm{dia}^{-1}$ recomenda-se o consumo de matéria seca de $2,8 \%$ do peso corporal, $1,714 \mathrm{~kg} \mathrm{dia}^{-1}$ de proteína e $8,53 \mathrm{~kg}$ dia $^{-1}$ de NDT. Todavia, esses valores são superiores ao sistema alimentar PSC que observou-se o maior consumo de MS\%PC, PB e NDT $\left(2,38,1,50,6,84 \mathrm{~kg} \mathrm{dia}^{-1}\right)$ respectivamente, todavia valores inferiores para suprir as exigências nutricionais de mantença e produção.

Não houve efeito do coeficiente de digestibilidade $(\mathrm{P}>0,10)$ para matéria seca MS; PB, FDN, CNF; e NDT em função dos sistemas alimentares (Tabela 6); provavelmente, devido a similaridade do comportamento alimentar referente à IMS dos animais (Tabela 5) e pela influência da composição química dos sistemas alimentares especificamente FDA (Tabela 2) sendo relacionado a digestibilidade. Deste modo, com a cinética e taxa de passagem da digesta pelo aparelho digestivo, a ingestão e digestibilidade são influenciados pela proporção da parede celular, pela resistência da forragem e pelas estruturas fibrosas que se rompem em pequenas particulas durante a mastigação e disgestão (BERCHIELLI et al., 2011).

O sistema alimentar PSC apresentou o melhor percentual de coeficiente de digestibilidade da matéria seca $49,29 \%$, o menor coeficiente para o PSS $45,84 \%$, em comparação aos percentuais aludido houve uma variação de $7,32 \%$. Os valores mencionados estão abaixo do recomendado entre 66 e $68 \%$ de digestibilidade, para obtenção de máxima ingestão de matéria seca, o maior percentual de MS ingerida foi proveniente do pasto que obteve $69,3 \%$ de FDN; $33,69 \%$ de FDA e $4,03 \%$ de lignina (Tabela 2) desta forma gramineas tropicais geralmente possuem digestibilidade inferior a $60 \%$. 
Observou-se efeito $(\mathrm{P}<0,10)$ sobre $\mathrm{o}$ coeficiente de digestibilidade do extrato etéreo (Tabela 6), possivelmente, pelas variações no teor de extrato etéreo nos alimentos que compunham os sistemas alimentares. Conquanto quando os níveis de extrato etéreo estão elevados, há redução na digestibilidade da fibra, não sendo observado nesta pesquisa (Tabela 2). O sistema alimentar PSC obteve melhor coeficiente de digestibilidade do extrato etéreo $77,79 \%$.
Quando comparado ao PSS 69,59\% observou-se uma diferença de 11,78\%. Provavelmente, ocorreu devido ao superior percentual do nutriente com base na MS do PSC em relação PSS (Tabela 2), conquanto observou-se também incremento na IMS influenciada pelo concentrado (Tabela 5). Desta forma, possivelmente, elevou-se o percentual de digestibilidade do extrato etéreo (Tabela 6).

Tabela 6. Médias dos coeficientes de digestibilidade dos nutrienetes dos sistemas alimentares

\begin{tabular}{lccccccc}
\hline \multirow{2}{*}{ Variável } & \multicolumn{9}{c}{ Sistemas alimentares } & \multirow{2}{*}{ EPM } & \multirow{2}{*}{ P } \\
\cline { 2 - 5 } & PE & PCU & PSC & PSSC & PSS & & 0,14 \\
MS & 46,54 & 46,74 & 49,29 & 47,47 & 45,84 & 6,95 & 0,64 \\
PB & 67,26 & 68,11 & 71,36 & 68,08 & 70.79 & 6,95 & 0,43 \\
FDN & 45,22 & 44,67 & 43,22 & 42,08 & 44,25 & 3,30 & 0,045 \\
EE & $75,14^{\mathrm{ab}}$ & $74,67^{\mathrm{ab}}$ & $77,79^{\mathrm{a}}$ & $70,37^{\mathrm{b}}$ & $69,59^{\mathrm{b}}$ & 6,06 & 0,37 \\
CNF & 75,78 & 75,60 & 81,52 & 81,67 & 73,89 & 8,21 & 0,30 \\
NDT & 49,48 & 49,33 & 51,64 & 50,04 & 48,76 & 2,48 & 0,48 \\
\hline
\end{tabular}

Médias seguidas de mesma letra na linha não diferem entre si pelo teste Tukey ao nível de (10\%) de probabilidade. $\mathrm{EPM}=$ Erro padrão da média; $\mathrm{P}=$ Probabilidade de erro. $\mathrm{PB}=$ proteína bruta; FDN = fibra em detergente neutro; $\mathrm{EE}=$ extrato etéreo; $\mathrm{CNF}=$ carboidrato não fibroso; NDT = nutrientes digestíveis totais; $\mathrm{PE}=$ pasto exclusivo; $\mathrm{PCU}$ = pasto associado à cana-de-açúcar e ureia; PSC = pasto associado ao suplemento concentrado; PSSC = pasto associado à silagem de sorgo e suplemento concentrado; PSS = pasto associado à silagem de sorgo.

Em relação ao desempenho das vacas, não houve efeito $(\mathrm{P}>0,10)$ sobre as variáveis estudadas produção leite; produção de leite corrigida para 4\% de gordura em $\mathrm{kg}$ dia $^{-1}$ e peso corporal em função dos sistemas alimentares (Tabela 7). A possível explicação devese ao reduzido incremento dos sistemas alimentares sobre o consumo de MS (Tabela 5). A ingestão voluntária de forragem foi a principal responsável para elevar o consumo de matéria seca total. O elevado teor FDN 69,3\% apresentado pelo pasto, proporcionou uma redução no coeficiente de digestibilidade da MS (Tabela 6). Segundo Berchielli et al. (2011), durante a disgestão da parade celular secundária, é improvável a digestão superficial e o acúmulo de monômeros fenólicos no lúmem celular em níveis tóxicos. Entretanto, a lenta difusão do complexo fenólico carboidrato poderá atingir concentrações tóxicas para as bactérias prejudicando, assim, o consumo e o coeficiente de digestibilidade da MS. Desta forma, houve uma menor contribuição dos nutrientes para a glândula mamária. Verifica-se que, quando existe limitação da utilização de nutrientes como a glicose, lactose, aminoácidos e ácidos graxos, reduz o desempenho das vacas, pois auxiliam na síntese do leite. 
No entanto, os valores encontrados nesta pesquisa, de 10 a $14 \mathrm{~kg}$ de leite $\mathrm{dia}^{-1}$, estão na faixa de vacas leiteiras que consomem pastagem tropical.

Mesmo não apresentando significância, o sistema alimentar em que foi observado maior tendência para produção de leite, foi o tratamento pasto associado ao suplemento concentrado PSC e menores índices produtivos para o pasto associado à silagem de sorgo PSS 10,$33 ; 9,86 \mathrm{~kg} \mathrm{dia}^{-1}$, respectivamente, no qual se constatou uma adição de $4,76 \%$, na produção de leite, o que poderia ser explicado em função do maior coeficiente de digestibilidade do suplemento concentrado proporcionado pela PB. O suplemento foi elaborado para atender às exigências de vacas com produção média de $15 \mathrm{~kg}$ de leite dia $^{-1} \mathrm{e}$ um consumo de $8 \mathrm{~kg}$ de NDT dia ${ }^{-1}$, segundo o NRC (2001). Os resultados encontrados nesta pesquisa ficaram abaixo do consumo de NDT em $\mathrm{kg} \mathrm{dia}^{-1}$ recomendado pelo NRC (2001), variando de 6,84 e $5,74 \mathrm{~kg}$ de NDT dia ${ }^{-1}$ para os sistemas alimentares PSC e PSS. Consequentemente, a produção de leite ficou abaixo do esperado, bem como as médias de produção corrigida para $4 \%$ de gordura (Tabela 7).

Em estudos sobre doses de $\mathrm{PB}$ em rações para vacas leiteiras de alta produção mantidas em confinamento, publicados no Journal of Dairy Science (KALSCHEUR et al., 2006; WANG et al., 2007; CYRIAC et al 2008; LAW et al., 2009), verificaram que as vacas alimentadas com rações com menos de $15 \%$ de PB tiveram suas produções de leite aumentadas de forma consistente, quando os teores de PB das rações foram elevados de 15 para $17 \%$. Todavia, na presente pesquisa verificou-se teor de $\mathrm{PB}$ $19,91 \%$ para tratamento PSC que não afetou $(\mathrm{P}>0,10)$ o consumo de matéria seca e a produção de leite em comparação aos demais sisemas alimentares. De acordo com a revisão de 82, estudos apresentados no NRC (2001), a produção de leite aumentou $0,75 \mathrm{~kg} / \mathrm{vaca} / \mathrm{dia}$ quando o teor de proteína bruta na ração foi aumentada de 15 para $16 \%$ e apenas $0,35 \mathrm{~kg} / \mathrm{dia}$. Quando o teor de proteína bruta foi aumentado de $19 \%$ para $20 \%$, a produção máxima de leite ocorreu com teores de $23 \%$ de $\mathrm{PB}$ na ração.

Tabela 7. Desempenho de vacas em lactação, em função dos sistemas alimentares

\begin{tabular}{lccccccc}
\hline \multirow{2}{*}{ Variável } & \multicolumn{9}{c}{ Sistemas alimentares } & \multirow{2}{*}{ EPM } & \multirow{2}{*}{ P } \\
\cline { 2 - 6 } & PE & PCU & PSC & PSSC & PSS & & \\
\hline PL $\left(\mathrm{kg} \mathrm{dia}^{-1}\right)$ & 10,16 & 10,03 & 10,33 & 10,26 & 9,86 & 2,73 & 0,90 \\
PLCG $^{4}\left(\mathrm{~kg} \mathrm{dia}^{-1}\right)$ & 9,99 & 9,75 & 9,90 & 10,13 & 9,91 & 2,55 & 0,99 \\
Peso Corporal & 566 & 570 & 557 & 565 & 563 & 29,11 & 0,45 \\
\hline
\end{tabular}

Médias seguidas de mesma letra na linha não diferem entre si pelo teste Tukey ao nível de (10\%) de probabilidade. $\mathrm{EPM}=$ Erro padrão da média; $\mathrm{P}=$ Probabilidade de erro. $\mathrm{PE}=$ pasto exclusivo; $\mathrm{PCU}=$ pasto associado à cana-de-açúcar e ureia; $\mathrm{PSC}=$ pasto associado ao suplemento concentrado; PSSC = pasto associado à silagem de sorgo e suplemento concentrado; PSS = pasto associado à silagem de sorgo.PL= produção de leite; $\mathrm{PLCG}=$ Produção de leite corrigida para gordura.

O aumento na produção de leite com a elevação no teor de $\mathrm{PB}$ da ração não esteve correlacionado com o consumo de matéria seca. Efeito positivo do aumento no teor de PB na ração no consumo de materia seca, é esperado quando a ração é deficiente em PDR. Essa ocorrência é mais comum em rações com teores de PB abaixo de 15\% NRC (2001). 
O peso corporal não foi influenciado pelos sistemas alimentares $(\mathrm{P}>0,10)$ provavelmente devido à similaridade do consumo de matéria seca em percentagem do peso corporal. Desta forma, possivelmente ocorreu uma similaridade entre a mobilização de reservas corporais para sustentar a mantença e a produção de leite dos animais.

Não houve efeito $(\mathrm{P}>0,10)$, em relação à composição do leite para proteína e gordura, bem como para as concentrações de nitrogênio ureico no leite em $\left(\mathrm{mg} \mathrm{dL} \mathrm{L}^{-1}\right)$ e em $\left(\mathrm{g} \mathrm{dia}{ }^{-1}\right)$ em função dos sistemas alimentares (Tabela 8). Esta homogeneidade entre os tratamentos provavelmente ocorreu pois, apresentou-se o pasto como principal fonte de alimentação, deste modo os sistemas alimentares não alteraram a IMS. Sendo assim, o aporte de nutrientes foi similar para a glândula mamária.

Mesmo não apresentando influência $(\mathrm{P}>0,10), \quad \mathrm{o}$ PSC obteve dado numericamente superior para à variável proteína 3,24\%. Nessa perspectiva, observou-se menor percentual para o $\mathrm{PE}$
2,94\% representando uma variação de $10,2 \%$ no valor proteico. Este acréscimo está relacionado ao maior consumo de MS e PB. Haja vista, que o suplemento concentrado proporcionou um superior percentual de digestibilidade, consequentemente ocorreu um acréscimo na síntese de proteína microbiana. No entanto, com a degradação da proteína no rúmen houve um fornecimento constante de peptídeos, aminoácidos e amônia para o crescimento dos microrganismos e consequentemente da síntese de proteína microbiana. Esse fato resultou em maior fluxo de proteína para o intestino delgado.

O NRC (2001) afirma que a proteína microbiana é $64 \%$ metabolizável e que a proteína metabolizável é usada para a lactação com eficiência de $67 \%$. A caseina a $\beta$-lactoglobulina e a $\alpha$ lactoalbumina correspondem a $95 \%$ das proteínas do leite sendo sintetizadas no úbere. Entretanto, a soro albumina as imunoglobulinas e a y-caseína não são sintetizadas no úbere e, simplesmente, são filtradas no sangue.

Tabela 8. Composição do leite e concentrações de nitrogênio ureico no leite de vacas lactantes em função dos sistemas alimentares

\begin{tabular}{|c|c|c|c|c|c|c|c|}
\hline \multirow{2}{*}{ Variável } & \multicolumn{5}{|c|}{ Sistemas alimentares } & \multirow{2}{*}{ EPM } & \multirow{2}{*}{$\mathrm{P}$} \\
\hline & $\mathrm{PE}$ & PCU & PSC & PSSC & PSS & & \\
\hline Proteína & 2,94 & 3,0 & 3,24 & 3,06 & 3,01 & 0,33 & 0,70 \\
\hline Gordura & 3,96 & 3,90 & 3,75 & 3,95 & 4,04 & 0,48 & 0,91 \\
\hline $\mathrm{N}(\mathrm{mg} / \mathrm{dL})$ & 2,46 & 3,10 & 3,02 & 2,99 & 2,98 & 1,02 & 0,19 \\
\hline $\mathrm{N}(\mathrm{g} / \mathrm{dia})$ & 0,26 & 0,33 & 0,31 & 0,29 & 0,32 & 0,16 & 0,58 \\
\hline
\end{tabular}

Médias seguidas de mesma letra na linha não diferem entre si pelo teste Tukey ao nível de (10\%) de probabilidade. $\mathrm{EPM}=$ Erro padrão da média; $\mathrm{P}=$ Probabilidade de erro; $\mathrm{PE}=$ pasto exclusivo; $\mathrm{PCU}=$ pasto associado à cana-de-açúcar e ureia; $\mathrm{PSC}=$ pasto associado ao suplemento concentrado; PSSC = pasto associado à silagem de sorgo e suplemento concentrado ; PSS = pasto associado à silagem de sorgo; $\mathrm{N}$ = nitrogênio.

A proteína metabolizável proporciona à glândula mamária maior disponibilidade de aminoácidos presentes na corrente sanguínea, principais precursores para a síntese de proteína do leite (PAIVA, 2013). A utilização de nitrogênio não proteíco pode alterar a composição da proteína do leite, influenciando no 
processamento industrial da matéria prima, já que os teores de proteína verdadeira e da caseina têm influência direta sobre a fabricação de derivados (AQUINO et al., 2009).

Em relação a percentagem de gordura do leite, o PSS apresentou-se superior $4,04 \%$ valores inferiores foram verificados para PSC 3,75. Em comparação aos sistemas alimentares citados, ocorreu uma variação de 7,73\% no percentual de gordura do leite. Dietas contendo concentrado com alto teor de amido reduz o teor gordura do leite. Em relação à dietas volumosas, o PSS apresentou um elevado teor de FDN (Tabela 2) que em sua fermentação no rúmen gera como produto os ácidos graxos de cadeia curta, entre eles percursores da síntese de gordura do leite como o acetato, $\beta$-Hidroxibutirato, triglicerídeos e glicose.

A síntese de triglicerídios da gordura do leite ocorre nas células epiteliais mamárias. Os ácidos graxos usados para sintetizar os triglicerídios provem dos lipídios do sangue e da síntese de novo dentro das células epiteliais mamárias. Há uma pequena, mas variável absorção de ácidos graxos livres pela glândula mamária. Aproximadamente de 40-60\% dos ácidos graxos encontrados no leite de vaca provém do sangue. Dietas com elevado teor de PB eleva o fornecimento de lisina e metionina desta forma pode estimular a via de nova síntese de ácidos graxos ou aumentar a síntese de quilomícrons e lipoproteínas de baixa densidade (NRC, 2001).

Mesmo não apresentando significância, ( $\mathrm{P}>0,10)$, o sistema alimentar que obteve maior concentração de nitrogênio ureico no leite foi PCU $\left(3,10 \mathrm{mg} \mathrm{dL}^{-1}\right) ;(0,33 \mathrm{~g}$ $\left.\mathrm{dia}^{-1}\right)$ quando comparado ao PE $(2,46 \mathrm{mg}$ $\left.\mathrm{dL}^{-1}\right) ;\left(0,26 \mathrm{~g}^{-1} \mathrm{dia}\right)$, apresentando um acréscimo de $26 \%\left(\mathrm{mg} \mathrm{dL}^{-1}\right)$ e $26,9 \%(\mathrm{~g}$ $\left.\mathrm{dia}^{-1}\right)$, respectivamente. Provavelmente pelo maior teor de proteina bruta verificado no PCU com base da MS (Tabela 2). A principal fonte de NNP utilizada em rações para ruminantes é a ureia; do ponto de vista nutricional é usada para adequar a ração em PDR (BERCHIELLI et al., 2011). A degradação da proteína no rúmem supre o abastecimento constante de peptídeos aminoácidos e amônia para o crescimento de microrganismos e conseguinte síntese microbiana.

O NRC (2001) recomenda-se para vacas em lactação com produção de $15 \mathrm{~kg}$ de leite com $4 \%$ de gordura, um consumo de $2,8 \%$ do peso corporal, correspondente a $14 \mathrm{~kg}$ de matéria seca, $1,714 \mathrm{~kg}$ de proteina bruta, $8 \mathrm{~kg}$ de nutrientes digestiveis totais para vacas com peso vivo médio de $500 \mathrm{~kg}$ - valores para suprir as exigências de mantença e produção. Contudo, os valores encontrados nesta pesquisa foram $2,16 \%$, $2,25 \%$ do peso corporal, $12,34,12,76 \mathrm{~kg}$ $\mathrm{dia}^{-1}$ de MS, 1,23, 1,26 kg dia ${ }^{-1}$ de PB, $6,08,6,32 \mathrm{~kg} \mathrm{dia}^{-1}$ de NDT para PCU em comparação ao PE. Todavia, os consumos ficaram abaixo do recomendado. Desta forma, os valores de nitrogênio ureico no leite (NUL) foram afetados, assim como seu desmpenho, pois os $\mathrm{o}$ a ingestão dos sistemas alimentares não atenderam as exigências nutricionais.

O nitrogênio ureico no leite auxilia na adequação do excesso de amônia ruminal em relação a energia diponível para o crescimento bacteriano no rúmem. A relação 7:1 NDT:PB, pode trazer informações importantes sobre $\mathrm{O}$ equilíbrio da dieta. Pois, a utilização do $\mathrm{N}$ no rúmen depende da presença de carboidratos que fornece energia $\mathrm{e}$ carbono possibilitando assim a fixação da amônia reduzindo sua perda através da absorção pelo rúmen, contribuindo para elevar a síntese de proteína microbiana. O teor de NUL deve se situar entre 10 a $16 \mathrm{mg}$ por decilitro $\mathrm{mg}$ 
$\mathrm{dl}^{-1}$, para determinar a adequação da nutrição protéica de vacas em lactação. Os valores avaliados ficaram abaixo do indicado (Tabela 8). Deste modo, o consumo PB e NDT foi fator limitante para todos os sistemas alimentares avaliados (Tabela 5). A otimização entre fonte de proteína microbiana $\mathrm{e}$ degradação de proteína no rúmen de vacas em lactação, é uma ferramenta importante para maximar a produção de leite, a eficiência do uso de $\mathrm{N}$ reduz as excreções de $\mathrm{N}$ para o ambiente (BERCHIELLI et al., 2011).

Portanto, diante de condições similares à esta pesquisa, no tocante ao período primavera-verão, recomenda-se para vacas mestiças holandês $\mathrm{x}$ zebu com produção média de $15 \mathrm{~kg}$ leite dia, ${ }^{-1} \mathrm{o}$ sistema alimentar pasto exclusivo da gramínea Urocloa decumbens. Assim, mesmo não atendendo as exigências nutricionais para o desempenho supracitado para a produção e composição química do leite é eventualmente mais viável.

\section{REFERÊNCIAS}

AQUINO, A.A.; PEIXOTO JUNIOR, K.C.; GIGANTE, M.L. Efeito de niveis crescentes de ureia na dieta de vacas leiteiras sobre a composicão e rendimento de fabricacão de queijos de minas frescal. Brazilian Journal of Veterinary Research and Animal Science, v.46, n.4,p.273-279, 2009.

BENEDETTI, E.; RODRÍGUEZ, N. M.; CAMPOS, W. E.; BORGES, A. L. C. C.; SALIBA, E. S. Consumo de alimentos e produção de leite de vacas mestiças mantidas em diferentes pastagens tropicais.Ciência Animal Brasileira[online], v.9, n.3, p.578-589, 2008.
BERCHIELLI, T.T.; PIRES, A.V.; OLIVEIRA, S. G. (Eds) Nutrição de ruminantes. 2 ed. Jaboticabal: Funep, 2011.611p.

BRASIL. Ministério da Agricultura, Pecuária e Abastecimento. Instrução Normativa No 11, de 30 de abril de 2009. Aprova os métodos oficiais alternativos para análise da qualidade do leite e seus derivados, que utilizem o sistema de detecção por diferencial de $\mathrm{pH}$ e reação enzimática - CL10 PLUS BCS. Diário Oficial da União, Brasília, DF, 4 maio 2009. Seção 1, p.12.

CYRIAC, J.; RIUS, A.G.; McGILLIARD, M.L.; PEARSON, R.E.; BEQUETTE, B.J.; HANIGAN, M.D. Lactation performance of mid-laction dairy cows fed ruminally degradable protein at concentarations lower than National Research Council Recommendations. Jornal of Dairy Science, v.91, n.12, p.4704-4713, 2008.

DETMANN, E.; SOUZA, M.A.; VALADARES FILHO, S.C.; QUEIROZ, A.C.; BERCHIELLI, T.T.; SALIBA, E.O.S.; CABRAL, L.S.; PINA, D.S.; LADEIRA, M.M.; AZEVEDO, J.A.G. Métodos para análise de alimentos INCT - Ciência Animal. Visconde do Rio Branco: Suprema, 2012. 214p.

KALSCHEUR, K.F.; BALDWIN, R.L.; GLENN, B.P.; KOHN, R.A. MILK PRODUCTION OF dairy cows fed differing concentrations of rumendegraded protein. Jounal of Dairy Science, v.89, n.1, p.249-259, 2006.

LAW, R.A.; YOUNG, F.J.; PATTERSON, D.C.; KILPATRICK, D.J.; WYLIE, A.R.; MAYNE, C.S. Effect of dietary protein content on animal production and blood metabolites of dairy cows during lactation. Jornal of Dairy Science, v.92, n.3, p.1001-1012, 2009. 
MARTINS, S.C.S.G.; ROCHA

JÚNIOR, V.R.; CALDEIRA, L.A.; PIRES, D.A.; BARROS, I.C.; SALES, E.C.J.; SANTOS, C.C.R; AGUIAR, A.C.R.; OLIVEIRA, C.R. Consumo, digestibilidade, produção de leite e análise econômica de dietas com diferentes volumosos. Revista Brasileira Saúde Produção Animal [online], v.12, n.3, p.691-708, 2011.

\section{NATIONAL RESEARCH COUNCIL -} NRC. Nutrient requirements of dairy cattle. 7 ed. Whashington, DC: National Academic Press, 2001. 381 p.

PAIVA, V.R.; LANA, R.P.; OLIVEIRA, A.S; LEÃO, M.I.; TEIXEIRA, R.M.A. Teores proteicos em dietas para vacas holandesas leiteiras em confinamento. Arquivo Brasileiro de Medicina Veterinária e Zootecnia [online], v.65, n.4, p.11831191, 2013.

\section{RECH, C. L.S (Org.). Manual prático} de analíse de alimentos para animais de interesse zootécnico. Vitória da Conquista, BA: UESB, 2010. 148p.

REIS, R.A.; DA SILVA, S.C. Consumo de forragens In: BERCHIELLI, T.T., VAZ PIRES, A., OLIVEIRA, S.G. (Eds.). Nutrição de Ruminantes. Jaboticabal: FUNEP, 2006. v.1, p.79109.

REIS, R.A.; RUGGIERI, A.C.; CASAGRANDE, D.R.; PÁSCOA, A.G. Suplementação da dieta de bovinos de corte como estratégia do manejo das pastagens. Revista Brasileira Zootecnia [online], v.38, p.147-159, 2009.
RIBEIRO FILHO, H.M.N.; HEYDT, M.S.; BAADE, E.A.S.; THALER

NETO, ANDRÉ. Consumo de forragem e produção de leite de vacas em pastagem de azevém-anual com duas ofertas de forragem. RevistaBrasileira de Zootecnia [online], v.38, n.10, p.2038-2044, 2009.

SILVA, C.V.; LANA, R.P.; CAMPOS, J.M..S.; QUEIROZ, A.C.; LEÃO, M.I.; ABREU, D.C.Consumo, digestibilidade aparente dos nutrientes e desempenho de vacas leiteiras em pastejo com dietas com diversos níveis de concentrado e proteína bruta. Revista Brasileira de Zootecnia [online], v.38, n.7, p.13721380, 2009.

\section{UNIVERSIDADE FEDERAL DE} VIÇOSA - UFV. SAEG: sistema para análises estatísticas. Versão 9.1. Viçosa, MG, 2007.

WANDERLEY, W. L.; FERREIRA, M. d.A.; BATISTA, A.M.V.; VÉRAS, A.S.C.; SANTOS, D.C.; URBANO, S.A; BISPO, S.V. Silagens e fenos em associação à palma forrageira para vacas em lactação. Consumo, digestibilidade e desempenho. Revista Brasileira de Saúde e Produção Animal [online], v.13, n.3, p.745-754, 2012.

WANG, C.; LIU, J.X.; YUAN, Z.P.; WU, Y.M.; ZHAI, S.W.; YE, H.W. Effect of level of metabolizable protein on milkproduction and nitrogen utilization in lactating dairy cows. Jornal of Deiry Science, v.90, n.6, p.2960-2965, 2007.

Data de recebimento: 19/04/2016

Data de aprovação: 02/12/2016 